\title{
Co-Existence of Myocardial Bridge, Thrombus and Stenosis in the Same Coronary Segment
}

\author{
Fatih Aygun ${ }^{\mathrm{a}, \mathrm{c}}$, Mehmet Vedat Caldirb ${ }^{\mathrm{b}}$, Ozgur Ciftci ${ }^{\mathrm{b}}$, Mehmet Ozulku ${ }^{\mathrm{a}}$, Murat Gunday ${ }^{\mathrm{a}}$
}

\begin{abstract}
Myocardial bridge is a congenital anomaly. It is identified by the tunneled major epicardial coronary artery, which courses intramurally and proceeds beneath the muscular bridge. Although it is traditionally considered as a benign condition, the literature reveals complications from ischemia until sudden death which have been associated with myocardial bridge. The case, which presented with the clinical picture of acute coronary syndrome and had atherosclerosis and thrombotic obstruction that accompany muscular bridge, which caused critical stenosis in left anterior descending (LAD) following coronary angiography, is the first case in literature. The present case has been introduced with difficulties encountered at treatment phase.
\end{abstract}

Keywords: Coronary artery; Myocardial bridge; Thrombosis; Arteriosclerosis

\section{Introduction}

Myocardial bridge is a congenital anomaly. It is identified by the tunneled major epicardial coronary artery, which courses intramurally and proceeds beneath the muscular bridge. This pathology was first recognized in 1737 by Reyman during autopsy, whereas it was first defined angiographically in 1960 by Portman and Iwing.

Myocardial bridge is usually limited to the mid segment of the left anterior descending (LAD) coronary artery. The main angiographic sign is the systolic press including epicardial coronary artery. Moreover, intracoronary Doppler studies demonstrated characteristic impairment in diastolic flow. The degree of press on coronary artery caused by myocardial

Manuscript accepted for publication April 16, 2015

${ }^{a}$ Baskent University, Konya Medical and Research Center, Cardiovascular Surgery, Konya, Turkey

bBaskent University, Konya Medical and Research Center, Cardiology, Konya, Turkey

${ }^{c}$ Corresponding Author: Fatih Aygun, Hoca Cihan Mahallesi Saray Caddesi No. 1, 42000 Selcuklu, Konya, Turkey. Email: fatihaygun@ttmail.com

doi: http://dx.doi.org/10.14740/jmc2151w bridge depends on the level of cardiac contractility, as well as length, thickness and localization of muscular bridge.

Although it is traditionally considered as a benign condition, the literature reveals complications such as ischemia, acute coronary syndrome, coronary spasm, ventricular septal laceration, arrhythmia, atrioventricular block, stunning, transient ventricular dysfunction, sudden death, and premature death following cardiac transplantation, which have been associated with myocardial bridge.

The case, which presented with the clinical picture of acute coronary syndrome and had atherosclerosis and thrombotic obstruction that accompany muscular bridge, which caused critical stenosis in LAD following coronary angiography, is first case in literature. The present case has been introduced with the literature owing to its clinical findings and the difficulties encountered at treatment phase.

\section{Case Report}

A 35-year-old male patient was admitted to the emergency room with chest pain that started at rest in the morning and has been extremely severe in the last $30 \mathrm{~min}$. He has had squeezing and burning-like chest pain during effort, or sometimes at rest, for approximately 1 month. He is receiving no medication. He has no family history of coronary artery disease. He has no hypertension, diabetes or hyperlipidemia, but smoking history of 1 package/day. On his physical examination, body temperature is $36.6^{\circ} \mathrm{C}$, blood pressure is $120 / 80 \mathrm{~mm} \mathrm{Hg}$, respiratory rate is $14 / \mathrm{min}$, pulse rate is $75 / \mathrm{min}$, and saturation by pulse oximeter is $98 \%$. Cardiac sounds are rhythmic, S1-S2 normal, and there is no extra heart sound or murmur. Both hemithoraces are equally involved in breathing and there is no rale or rhonchi. Abdomen is loose with no distension, rebound or tenderness. Peripheral pulses are palpable. On laboratory analyses, the only pathological finding was troponin-I, which was found to be $0.174 \mathrm{ng} / \mathrm{mL}$ (normal range: $0-0.033 \mathrm{ng} /$ $\mathrm{mL}$ ). Electrocardiography revealed ST elevation in the anterior leads (Fig. 1). The patient was immediately admitted to the coronary angiography $(\mathrm{CAG})$ laboratory for percutaneous intervention. The CAG demonstrated normal left main coronary artery; muscular bridge that caused stenosis over $95 \%$ in the mid segment of the LAD during systole and thrombotic obstruction that caused stenosis by $70 \%$ in the same segment 


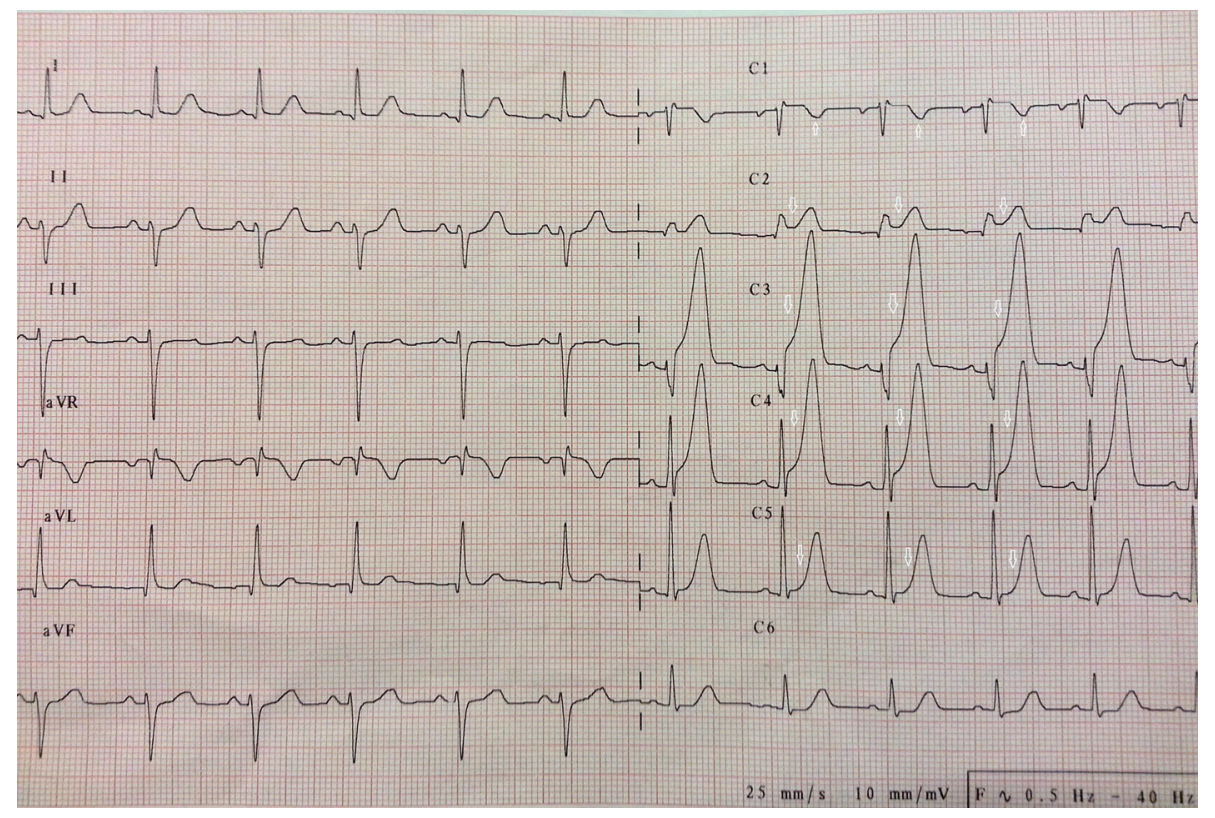

Figure 1. ECG of the case at the time of admission to emergency room.

during diastole (Fig. 2); normal circumflex artery; and normal right coronary artery. Three flows were detected in the thrombolysis in myocardial infarction (TIMI) in distal LAD. At this point, antithrombotic and antiaggregant treatment was commenced including enoxaparin sodium (8000 anti-Xa IU, $2 \times 1$ /day via subcutaneous route), acetyl salicylic acid (300 $\mathrm{mg}$ tablet, $1 \times 1$ /day via oral route), clopidogrel $(75 \mathrm{mg} 1 \times 1$ via oral route ), metoprolol (50 $\mathrm{mg}$ tablet, $2 \times 1 /$ day via oral route), and tirofiban hydrochloride monohydrate infusion (10 $\mu \mathrm{g} / \mathrm{kg}$ as 3-min bolus injection followed by $0.15 \mu \mathrm{g} / \mathrm{kg} / \mathrm{min}$ maintenance dose). After $30 \mathrm{~min}$, it was observed that chest pain relieved and ST elevation on the ECG regressed (Fig. 3), and angiographic improvement was determined. The patient

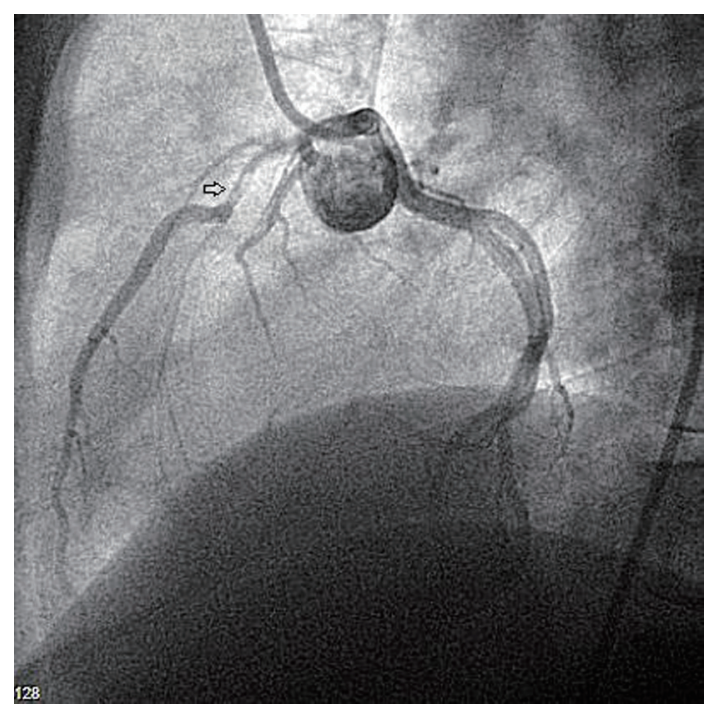

Figure 2. LAD intralesional thrombus (black arrow). underwent angiography again after being treated for $24 \mathrm{~h}$ and it was observed that the lesion in LAD has persisted (Fig. 4, $5)$. Therefore, we wavered between percutaneous intervention to the lesion and coronary artery bypass graft (CABG) surgery; however, it was decided to perform surgical intervention to the coronary artery as the literature revealed that complications due to the stents implanted in the places where muscular bridges exist are more frequent.

\section{Discussion}

Myocardial bridge was first described anatomically in 1737 by Reyman and then in 1805 by Black as a muscular configuration extending over the left descending coronary artery [1]. Until now, many studies have been published that associate the infarctions in young patients, who had muscular bridge without coronary atherosclerosis and in whom acute myocardial infarction has been identified, to myocardial bridges [2].

This anatomic configuration has pathophysiological structure. Studies demonstrated that these muscular bands are present since birth [3]. Incidence rates show variations. The incidence of myocardial bridge determined by $\mathrm{CAG}$ is reported between $1.5 \%$ and $16 \%$, whereas it is reported to reach $80 \%$ in autopsy series [4]. The LAD coronary artery is the most important artery influenced by muscular bridges. Anatomical studies demonstrate that muscular bridges exist between proximal one-third and middle one-third segments [5]. Some scientists have tried to classify muscular bridges. Geiringer divided the muscular bridges into two groups. In the first type, it is surrounded by muscular structure and courses along the deep of interventricular sulcus, whereas in the second type, muscular bridge originates from trigonum fibrosum and surrounds the LAD up to the apex of the heart [2]. 


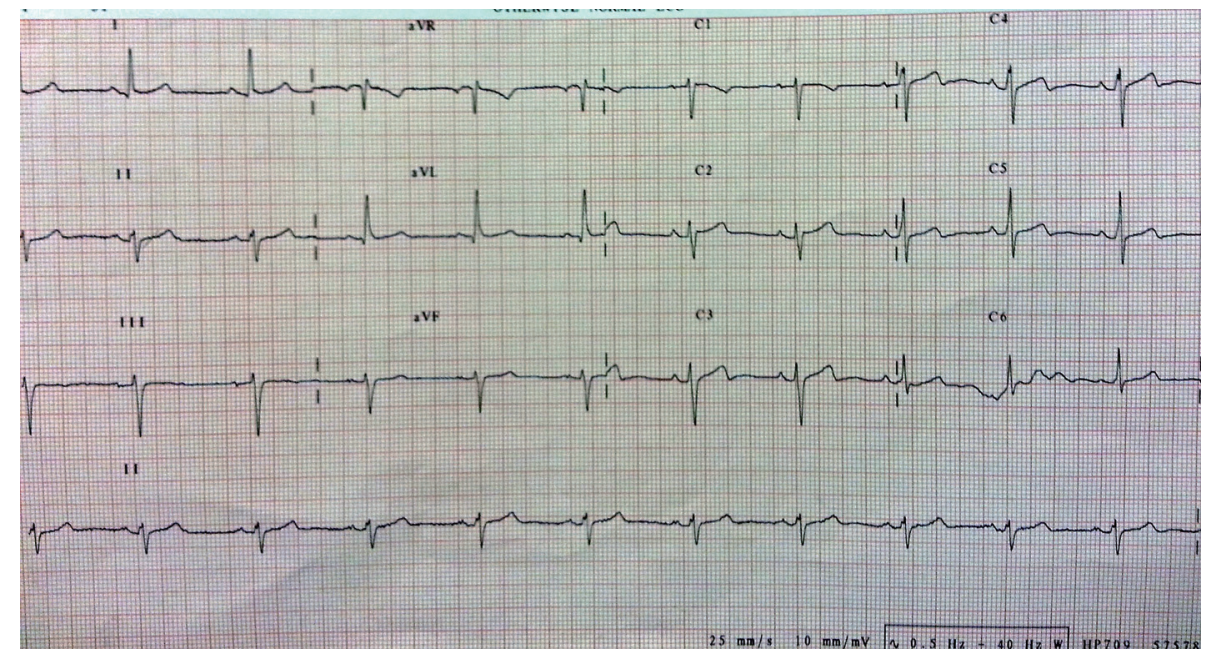

Figure 3. ECG of the case after medical treatment.

The relation between ischemia and myocardial bridges is well defined and symptoms are removed by surgical excision of myocardial bridges [6]. Hill et al demonstrated that distortion may develop during systole and relaxation would be delayed during diastole when LAD artery coursed beneath muscular bridge [7]. Nevertheless, some individuals with muscular bridge are asymptomatic [8].

Ishimori et al reported that giving glycerol nitrate while using vasoactive medication in the patients with myocardial bridge did not musk LAD stenosis and resulted in ischemia in some cases [9].

Therapeutic approach includes beta blockers, calcium channel blockers, stents, minimal invasive CABG surgery, and

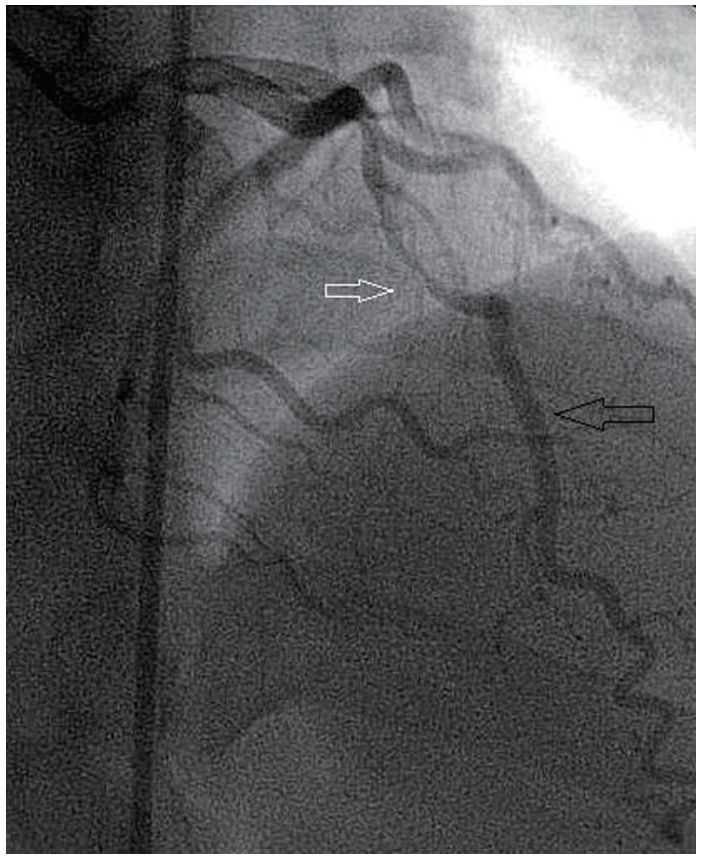

Figure 4. Images of myocardial bridge and LAD during systole on coronary angiography (black arrow LAD). surgical myotomy. Nitrate administration is not recommended since it enhances systolic stenosis and worsens symptoms. Although there is no study demonstrating that myocardial perfusion defect has been normalized before stent implantation, Klues et al expressed that stent implantation may remove hemodynamic abnormalities and may improve symptoms. Haager et al followed 11 patients without any lesion except for symptomatic muscular bridge in central position and had stent implanted in this region. They observed minimal increase in mean lumen diameter after stent implantation. They demonstrated that this increase is significant with IVUS. However, $50 \%$ of the patients developed mild-to-severe stenosis during 7-week follow-up period and two patients underwent PTCI,

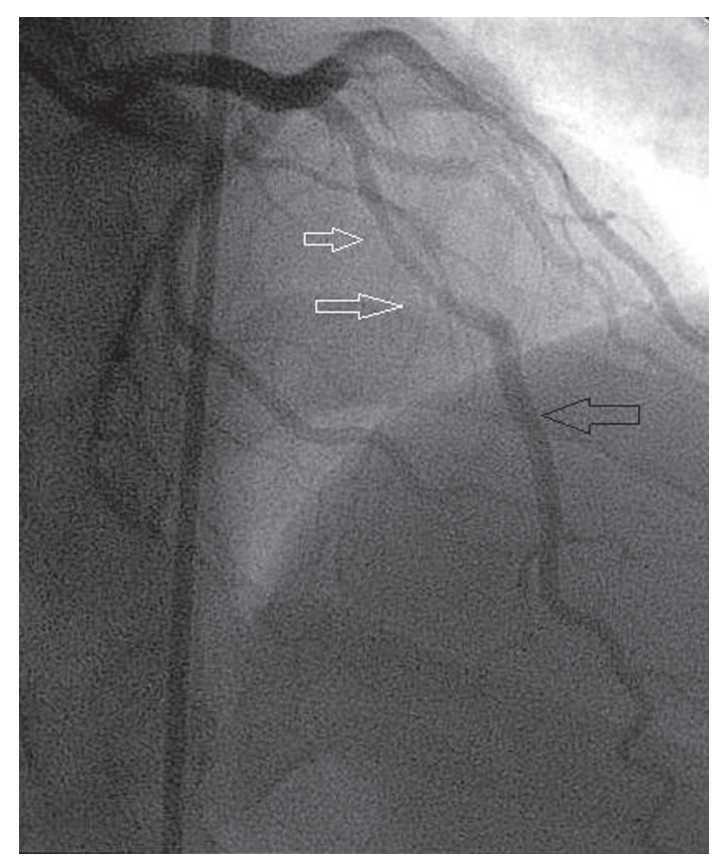

Figure 5. Image of coronary lesion in the mid segment of LAD during diastole on coronary angiography (black arrow LAD). 
whereas two patients underwent CABG. Two-year clinical follow-up showed no abnormality. Haager et al emphasized that the stent they had used has modified modular structure with flexible sulcus.

Myocardial bridge in the LAD and coronary atherosclerotic lesion in the same localization accompanied by thrombus is not a common condition. In conclusion, it was difficult to make a therapeutic decision in the present case because of his age and presence of atherosclerotic thrombotic lesion, which caused diastolic stenosis and persisted despite optimal medical therapy. In the literature, surgical myotomy or CABG are preferred to percutaneous coronary stent implantation because of high risk of intra-stent restenosis in the regions where myocardial bridges exist [10]. Under the light of literature, we as well made our decision in favor of coronary bypass surgery. However, we decided to publish the present case in order that treatment protocols for this clinical condition with high morbimortality should be discussed and reevaluated.

\section{References}

1. Reyman HC. Diss de vasis cordis propriis. Bibl Anat. 1737;2:359-379.

2. Geiringer E. The mural coronary. Am Heart J. 1951;41(3):359-368.

3. Polacek P, Kralove H. Relation of myocardial bridges and loops on the coronary arteries to coronary occulsions. Am
Heart J. 1961;61:44-52.

4. Rossi L, Dander B, Nidasio GP, Arbustini E, Paris B, Vassanelli C, Buonanno C, et al. Myocardial bridges and ischemic heart disease. Eur Heart J. 1980;1(4):239-245.

5. Bezerra AJ, Prates JC, DiDio LJ. Incidence and clinical significance of bridges of myocardium over the coronary arteries and their branches. Surg Radiol Anat. 1987;9(4):273-280.

6. Marshall ME, Headley RN. Intramural coronary artery as a cause of unstable angina pectoris. South Med J. 1978;71(10):1304-1306.

7. Hill RC, Chitwood WR, Jr., Bashore TM, Sink JD, Cox JL, Wechsler AS. Coronary flow and regional function before and after supraarterial myotomy for myocardial bridging. Ann Thorac Surg. 1981;31(2):176-181.

8. Loures JB, Sousa JE, Pimentel WA, Freire RJ, Buchler JR, Gizzi JC, Fontes VF, et al. [Hemodynamic and metabolic study of patients with myocardial bypass of the anterior descending artery]. Arq Bras Cardiol. 1978;31(3):159165 .

9. Ishimori T, Raizner AE, Chahine RA, Awdeh M, Luchi RJ. Myocardial bridges in man: clinical correlations and angiographic accentuation with nitroglycerin. Cathet Cardiovasc Diagn. 1977;3(1):59-65.

10. Tsujita K, Maehara A, Mintz GS, Doi H, Kubo T, Castellanos C, Liu J, et al. Impact of myocardial bridge on clinical outcome after coronary stent placement. Am J Cardiol. 2009;103(10):1344-1348. 